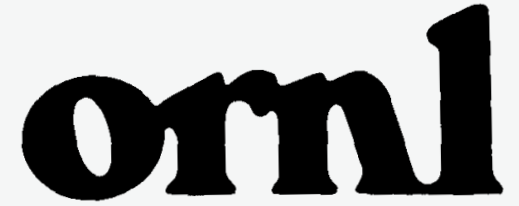

OAK RIDGE NATIONAL LABORATORY

LOCKUED MATIM

\title{
HFIR Vessel Probabilistic Fracture- Mechanics Analysis
}

R. D. Cheverton

T. L. Dickson

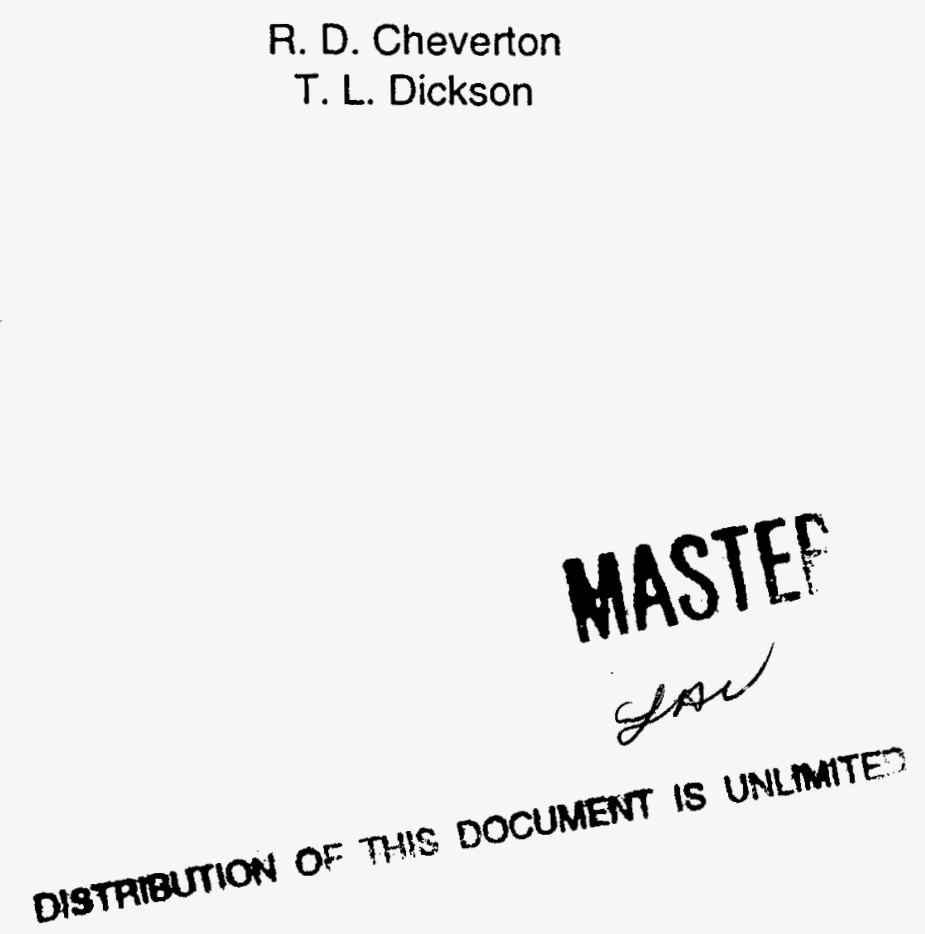

MANAGED AND OPERATEO BY

LOCKHEEO MARTIN ENERGY RESEARCH CORPORATION FOATHE UNTED STATES DEPARTMENT OF ENERGY 
This repor has been reproduced directly from the best available copy.

Available to DOE and DOE contractors from the Office of Scientific and Technical Information, P. O. Box 62, Oak Ridge. TN 37831: prices available from (423) 576-8401. FTS 626-8401.

Available to the public from the National Technical Information Service. U.S. Department of Commerce. 5285 Port Royal Road. Springfield. VA 22161.

This report was prepared as an account of work sponsored by an agency of the United States Government. Neither the United States Government nor any agency thereof, nor any of their employees, makes any warranty, express or implied, or assumes any legal liability or responsibility for the accuracy. completeness, or usefulness of any information, apparatus, product, or process disclosed. or represents that its use would not infringe privately owned rights. Reference herein to any specific commercial product, process, or service by trade name. trademark, manufacturer, or otherwise. does not necessarily constitute or imply its endorsement, recommendation, or favoring by the United States Government or any agency thereof. The views and opinions of authors expressed herein do not necessarily state or reflect those of the United States Govemment of anv agency thereof. 
ORNL/TM-13303

\title{
HFIR VESSEL PROBABILISTIC \\ FRACTURE-MECHANICS ANALYSIS
}

\author{
R. D. Cheverton \\ Delta-21 Resources, Inc. \\ T. L. Dickson \\ Oak Ridge National Laboratory \\ January 1997
}

\author{
Prepared by \\ OAK RIDGE NATIONAL LABORATORY \\ Oak Ridge, Tennessee 37831-6285 \\ managed by \\ LOCKHEED MARTIN ENERGY RESEARCH INC. \\ for the \\ U. S. DEPARTMENT OF ENERGY \\ under contract DE-AC05-960R22464
}




\section{TABLE OF CONTENTS}

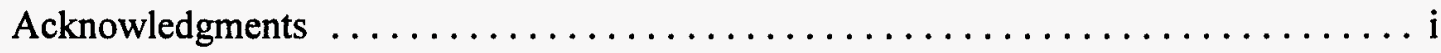

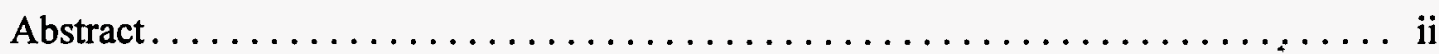

1. Introduction $\ldots \ldots \ldots \ldots \ldots \ldots \ldots \ldots \ldots \ldots \ldots \ldots \ldots \ldots \ldots \ldots, 1$

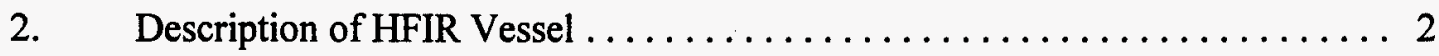

3. Loads on Vessel $\ldots \ldots \ldots \ldots \ldots \ldots \ldots \ldots \ldots \ldots \ldots \ldots \ldots \ldots$

4. Critical Regions of Vessel $\ldots \ldots \ldots \ldots \ldots \ldots \ldots \ldots \ldots \ldots \ldots$

4.1 Potential for propagation of flaws $\ldots \ldots \ldots \ldots \ldots \ldots \ldots \ldots \ldots, 6$

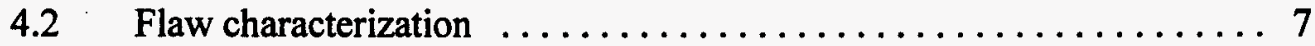

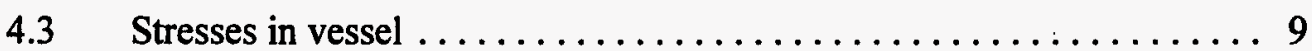

4.4 The $\mathrm{K}_{\mathrm{Ic}}$ curve $\ldots \ldots \ldots \ldots \ldots \ldots \ldots \ldots \ldots \ldots \ldots \ldots \ldots \ldots \ldots \ldots \ldots \ldots$

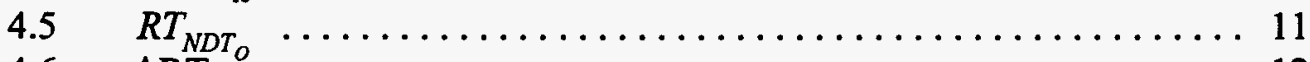

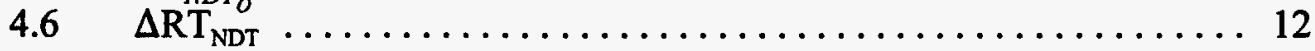

$4.7 \quad$ Region area and flaw density $\ldots \ldots \ldots \ldots \ldots \ldots \ldots \ldots \ldots \ldots \ldots \ldots$

4.8 Region definition $\ldots \ldots \ldots \ldots \ldots \ldots \ldots \ldots \ldots \ldots \ldots \ldots \ldots \ldots, 13$

5. Brief Description of the Probabilistic Fracture Mechanics Code FAVOR $\ldots .14$

$5.1 \quad$ Origin of FAVOR $\ldots \ldots \ldots \ldots \ldots \ldots \ldots \ldots \ldots \ldots \ldots \ldots \ldots \ldots \ldots \ldots \ldots$

5.2 Quality-assurance assessment $\ldots \ldots \ldots \ldots \ldots \ldots \ldots \ldots \ldots \ldots \ldots \ldots \ldots \ldots$

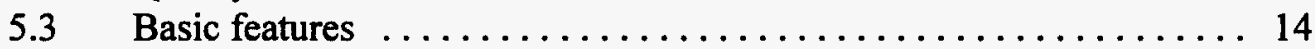

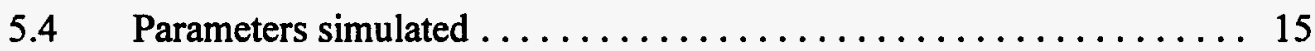

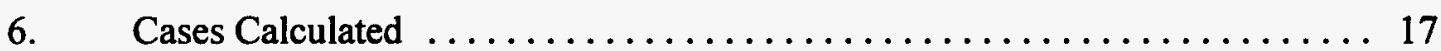

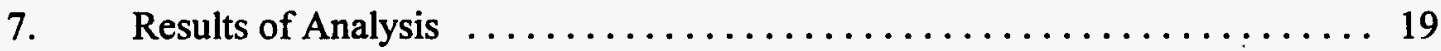

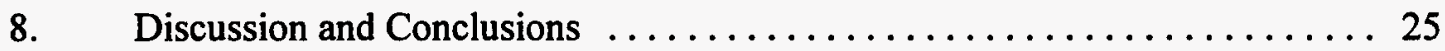

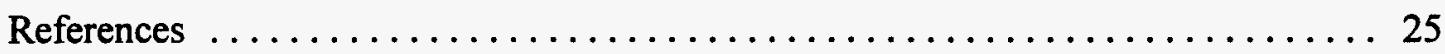

Appendix A: Derivation of Stress in Regions of the Vessel Defined for Probabilistic Fracture-Mechanics Analysis . ............. 28

Appendix B: Flaw-Depth Increments Used in Flaw-Depth Distribution

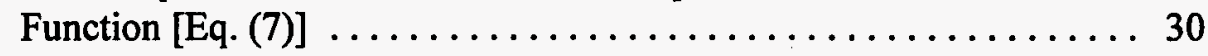




\section{ACKNOWLEDGMENTS}

The authors wish to acknowledge the contributions made by J. R. Inger (ORNL/RRD task leader), S. J. Chang and J. G. Merkle (peer review), and Mary Wells (preparation of manuscript). 


\begin{abstract}
The life of the High Flux Isotope Reactor (HFIR) pressure vessel is limited by a radiationinduced reduction in the material's fracture toughness. Hydrostatic proof testing and probabilistic fracture mechanics analyses are being used to meet the intent of the ASME Code, while extending the life of the vessel well beyond its original design value. The most recent probabilistic evaluation is more precise and accounts for the effects of gamma as well as neutron radiation embrittlement. This analysis confirms the earlier estimates of a permissible vessel lifetime of at least 50 EFPY (100 MW).
\end{abstract}




\section{HFIR VESSEL PROBABILISTIC FRACTURE-MECHANICS ANALYSIS}

\section{Introduction}

The life of the High Flux Isotope Reactor (HFIR) pressure vessel is limited by a radiationinduced reduction in the material fracture toughness. The reduction in toughness increases the chances that a sharp, crack-like defect (flaw) will propagate through the vessel wall, resulting in vessel failure. With this in mind, the HFIR vessel was designed for 20 EFPY (100 MW)." In November 1986, at which time the vessel had accumulated 17.5 EFPY (100 $\mathrm{MW})$, the vessel surveillance program ${ }^{1}$ revealed that the radiation-induced degradation rate was substantially greater than expected, and that criteria for "safe" operation had been violated. ${ }^{2}$ A reevaluation of vessel integrity, using updated methods of analysis, indicated that the associated ASME Code requirements could not be satisfied for a desired life extension of 8.5 EFPY (100 MW). Thus, hydrostatic proof testing was resorted to as a means of satisfying the intent of the Code while extending the life of the vessel. ${ }^{2}$

If the hydro-test conditions (pressure, temperature, and frequency) are selected properly, the vessel can, in principle, be used until it fails during a hydro test. Although not a safety issue, failure of the vessel during a hydro test is not desirable. Unfortunately, a successful test (nonfailure) does not reveal what the chances of failure are for the next test. The chances, however, can be estimated using probabilistic fracture-mechanics methods of analysis such as those developed by the Oak Ridge National Laboratory (ORNL) for the evaluation of the integrity of commercial pressurized water reactor (PWR) pressure vessels. ${ }^{3,4}$

Hydro-test conditions for the HFIR vessel are determined analytically by specifying that the potential for vessel failure during the hydro test must be at least equal to that for worst-case operating conditions [referred to herein as emergency/faulted (E/F) conditions]. ${ }^{2,5,6,7}$ Although the hydro-test conditions are determined with a deterministic analysis, the implication is that the calculated probability of failure during the hydro test must be at least equal to that for the $\mathrm{E} / \mathrm{F}$ condition. Thus, once the hydro-test conditions are calculated, the

*20 effective-full-power years based on full power $=100 \mathrm{MW}$. 
probability of vessel failure is calculated for both the hydro-test and E/F conditions and compared.

A successful hydro test provides assurance that the vessel will not fail during the time between hydro tests when subjected to the $\mathrm{E} / \mathrm{F}$ condition. However, additional assurance is provided by comparing the calculated frequency of failure (frequency of event times conditional probability of failure) for the E/F condition with accepted criteria. ${ }^{6}$ This reinforces the need for calculating the probability of failure for the $\mathrm{E} / \mathrm{F}$ as well as the hydrotest conditions.

A probabilistic analysis performed in 1987 indicated that the desired 8.5 EFPY (100 MW) life extension beyond 17.5 EFPY (100 MW) could be achieved. ${ }^{2}$ In early 1994, an update of the analysis, ${ }^{5}$ using additional surveillance data, indicated a useful life well beyond 17.5 $+8.5=26.0$ EFPY $(100 \mathrm{MW})$, and by the latter part of 1994 , after a need for life extension beyond 26 EFPY (100 MW) had been established, a 50 EFPY (100 MW) life time was estimated. ${ }^{6}$ By the early part of 1996 , the effect of gammas on the distribution of radiationinduced degradation was considered, but this appeared to have little effect on the predicted life of the vessel. ${ }^{7}$ At that point in the analysis, however, a considerable amount of interpolation and extrapolation of the probabilistic results was involved. To reduce the uncertainty, an updated probabilistic analysis was performed, and that analysis is the subject of this report. In summary, the results of the latest study indicate a somewhat lower calculated probability of failure than reported in the most recent previous study. ${ }^{7}$ Thus, based on the criteria developed in Ref. 6 and applied in Ref. 7, the results of this study indicate that a total life of the HFIR vessel of at least 50 EFPY $(100 \mathrm{MW})$ is feasible.

\section{Description of HFIR Vessel ${ }^{2}$}

As indicated in Figs. 1 and 2, the region of the vessel opposite the reactor core is cylindrical with a single axial seam weld and a diameter of $\sim 8 \mathrm{ft}$. A circumferential weld that attaches the cylindrical region to a hemisphical bottom section is located about 9 in. below the bottom 
ORNL/TM-13303

OANL-OWG 87-4673 ETO

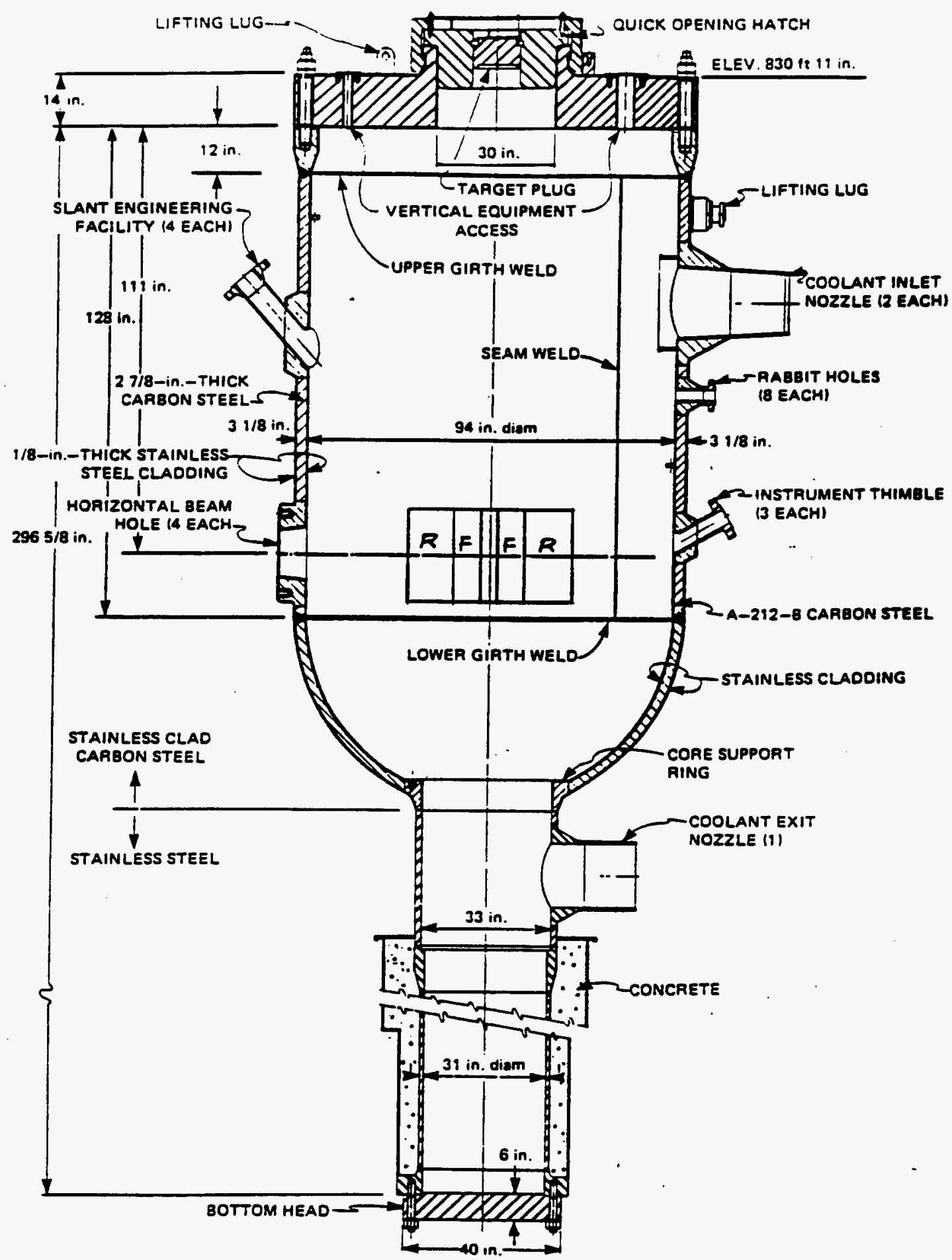

Fig. 1. Vertical cross section of HFIR pressure vessel, showing location of fuel $(F)$ and beryllium reflector $(R)$. 
ORNL/TM-13303

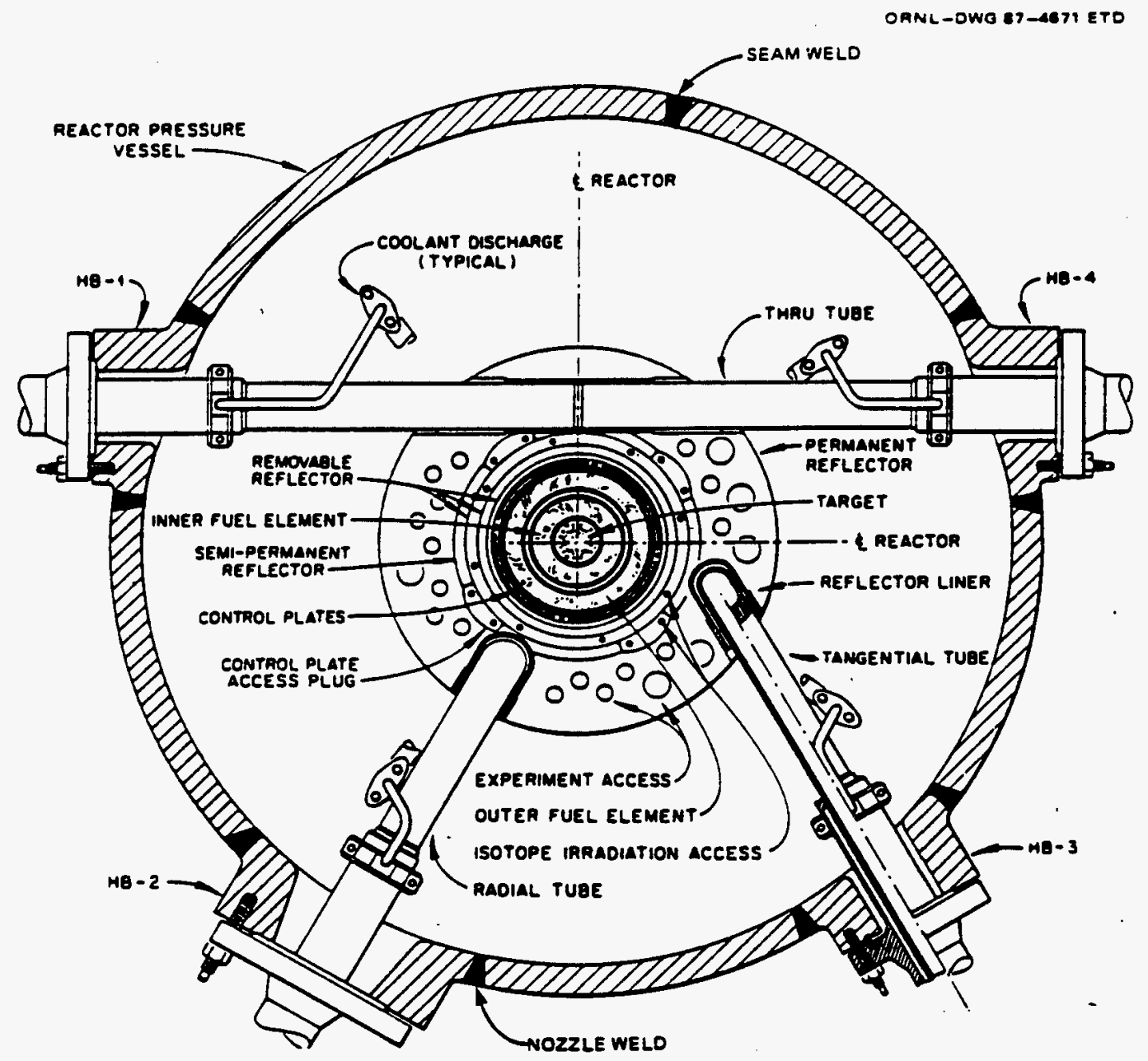

Fig. 2. Horizontal cross section of HFIR pressure vessel and core at horizontal midplane of core. 
end of the fuel. At an elevation corresponding to the horizontal midplane of the core, there are four nozzles that allow beam tubes to pass through the vessel wall.

The shell material for the 8-ft-diam section and the hemispherical section is A212B, a lowalloy carbon steel. The single section of plate was roll-bond clad on the inner surface with 304L stainless steel. After weld-assembly of all sections, the vessel was weld-deposit clad on the outer surface and on the inner-surface weld joints with 347 stainless steel. The four beam-tube nozzles were machined from forgings that were A105II material for HB-1 and HB-4 and A350LF3 for HB-2 and HB-3. These forging materials are low-alloy carbon steels that have substantially greater initial fracture toughness than that for the shell material (A212B). ${ }^{2}$ The nozzle exposed surfaces were also weld-deposit clad with 347 stainless steel.

All the vessel assembly welds were subjected to a stress-relief heat treatment. However, considering the low pressure at which the HFIR vessel operates, relative to its initial design pressure, the remaining residual stresses were not negligible.

\section{Loads on Vessel}

As indicated in the "Introduction," there are two extreme loading conditions that must be considered: emergency/faulted (E/F) and hydro test. Any other credible loading condition is less severe and thus need not be included in the probabilistic analysis.

For the E/F condition, the only significant load applied to the HFIR vessel is internal pressure that is applied by the primary system pressurizer pumps. It is possible that the present pressurizer pumps and associated controls could malfunction and result in a higher than normal pressure. However, the primary system is protected by rupture discs. A primarysystem pressure equal to the burst pressure of the rupture discs is considered to be credible (estimated frequency $=7 \times 10^{-5} \mathrm{y}^{-1}$ ), but a higher pressure is not (estimated frequency $=7 \times$ $\left.10^{-11} \mathrm{y}^{-1}\right) .^{6}$ Thus, the rupture-disc pressure specified for normal operation was considered to be the $E / F$-condition pressure $[p(E / F)]$. The vessel temperature associated with the $E / F$ 
condition $\left[T_{v}(E / F)\right]$ was based on the minimum expected temperature of the secondary coolant in the cooling-tower basin. ${ }^{7}$

The hydro-test pressure $[\mathrm{p}(\mathrm{HT})]$ is substantially greater than $\mathrm{p}(\mathrm{E} / \mathrm{F})$ to accommodate degradation of the vessel between hydro tests; ${ }^{6}$ the hydro-test temperature $\left[T_{v}(H T)\right]$ is a convenient value. ${ }^{6}$

\section{Critical Regions of Vessel}

\subsection{Potential for propagation of flaws}

The critical regions of the vessel are those that contribute significantly to the calculated probability of vessel failure. As discussed in more detail in Refs. 2-6, the potential for propagation of flaws can be defined as $\mathrm{K}_{\mathrm{I}} / \mathrm{K}_{\mathrm{lc}}$, where $\mathrm{K}_{\mathrm{I}}$ is the stress intensity factor, and $\mathrm{K}_{\mathrm{Ic}}$ is the material fracture toughness. These parameters can be further defined as follows: ${ }^{2}$

$$
\begin{gathered}
K_{I}=(\pi a)^{1 / 2} \sum_{n} c_{n} \sigma_{n}, \\
K_{I c}=A+B \exp \left[C\left(T_{v}-R T_{N D T_{o}}-\Delta R T_{N D T}\right)\right], \\
\Delta R T_{N D T}=\Delta N D T T,
\end{gathered}
$$

where

$$
\begin{array}{ll}
a & =\text { flaw depth } \\
c_{n} & =\text { flaw characterization factor for stress } \sigma_{n} \\
\sigma_{n} & =\text { type-n stress (membrane, bending, residual, thermal) } \\
A, B, C & =\text { constants } \\
T_{v} & =\text { temperature of vessel } \\
R T_{N D T_{o}} & =\text { initial value of the reference nil-ductility temperature } \\
\Delta R T_{N D T} & =\text { increase in } \mathrm{RT}_{\mathrm{NDT}} \text { due to radiation }
\end{array}
$$


$\triangle N D T T=$ increase in the nil-ductility transition temperature

The number of flaws in the vessel also affects the potential for failure, and the greater the surface area of the defined region the greater the number of flaws.

The above parameters, in one form or another, are used in the probabilistic fracturemechanics analysis to define critical regions of the vessel. Different regions may have different values of at least some of the parameters and thus have different potentials for propagation of flaws. Each of the parameters is discussed in further detail below with regard to their application in the HFIR study.

\subsection{Flaw characterization}

Flaws with the greatest potential for propagation are inner-surface flaws normal to the surface and to the direction of the maximum principal stresses, other things being equal. Thus, all flaws considered were of this type.

The flaw shape considered for HFIR was semielliptical (Fig. 3) and the aspect ratio (surface length/depth) was 6, the value specified in the ASME Code for design purposes. ${ }^{8}$ Flaws with larger aspect ratios have a greater potential for propagating but a lower probability of existing.

Because of the different orientations of the welds in the vessel, the flaws in different regions could also have different orientations. However, for the regions that contribute significantly to the probability of failure, only axial flaws are considered.

The flaw characterization factor $\left(c_{n}\right)$ is not used as such in the HFIR probabilistic analysis because the $\mathrm{K}_{\mathrm{I}}$ values are effectively calculated using a finite-element approach, which models the flaw and associated stresses in detail. 


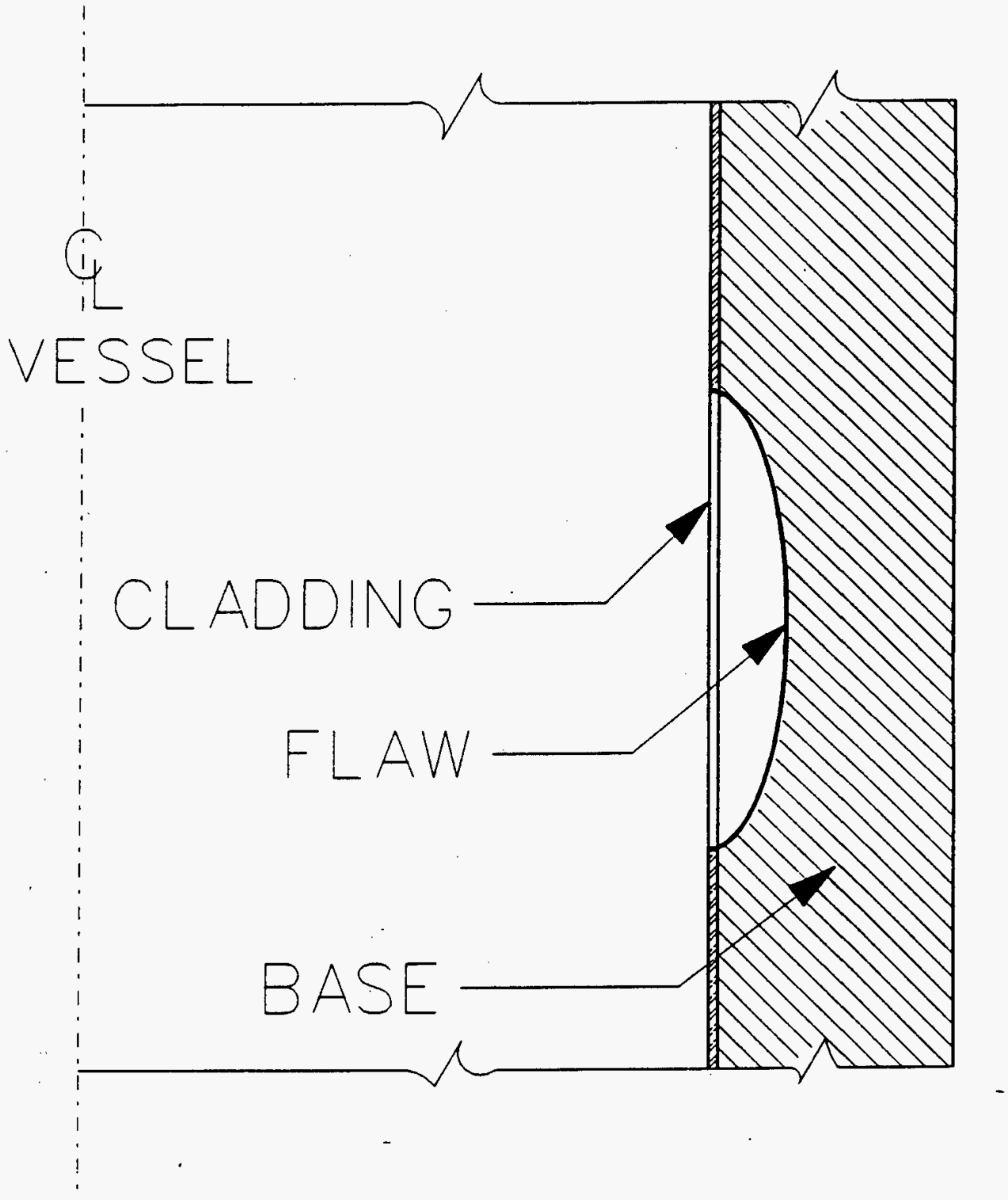

Fig. 3. Axially oriented, semielliptical, surface flaw used in HFIR fracture analysis. 
For the type of flaw selected, the value of $\mathrm{K}_{\mathrm{I}} / \mathrm{K}_{\mathrm{Ic}}$ is a maximum at the deepest point of the flaw, and thus calculations were made for that location only. Furthermore, it was assumed that once propagation begins at the deepest point, the flaw will grow in surface length, allowing it to grow deeper and thus through the wall in a single event. There may be some conservatism involved in this assumption, but the mechanics are too complex to allow quantification.

\subsection{Stresses in vessel}

The stress in the shell region away from the nozzles and welds is simply the pressure-induced membrane stress $\left(\sigma_{m}\right)$. Close to a nozzle the membrane stress varies some around the nozzle, and there is also a discontinuity bending stress $\left(\sigma_{b}\right)$ that varies around the nozzle and through the wall. Welds around the nozzles are subjected to membrane stresses, bending stresses, and residual stresses $\left(\sigma_{\tau}\right)$, the latter of which has a component transverse to the weld direction and one in the direction of the weld. The seam welds are subjected to membrane and residual stresses.

Because of the difference in temperature between the primary-system coolant in the vessel outer region and the water in the reactor pool, there is also a thermal stress. However, this stress is relatively small and thus has been omitted from the study.

Differential thermal expansion between the cladding (relatively high temperature and coefficient of thermal expansion) and the base material during cooling of the vessel from fabrication temperatures tends to result in high tensile stresses in the cladding and a relatively low compressive reaction stress in the base material. The effect of these stresses on the stress intensity factor associated with a flaw depends upon the depth of the flaw. The deeper the flaw the greater the effect of the stress in the base material and the less the effect of the stress in the cladding. "All" flaw depths are considered in the probabilistic analysis. Aside from flaw depth, if the potential for propagation of flaws is high, shallow flaws will result in most failures (more shallow than deep flaws and lower fracture toughness), and the high differential-expansion stress in the cladding will be influential. On the other hand, if the 
potential is low, the flaw depths resulting in failure will be relatively large and the cladding effect relatively small. Preliminary calculations indicated that the critical flaw depths were large enough that the cladding effect resulted in a smaller stress intensity factor and thus a lower probability of failure. Because there is considerable uncertainty about the actual stress in the cladding (for instance, the stress may be less than assumed because of radiation stressrelief effects), and because the effect of cladding is to result in a lower calculated probability of failure, the cladding stresses and associated reaction stresses in the base material were not included in the final analysis. In this regard, the results tend to be conservative.

Stresses in critical areas of the HFIR vessel are given in Ref. 2 and Table 1 and are derived in Appendix A.

Table 1. Characterization of regions of HFIR vessel selected for probabilistic fracture-mechanics analysis

\begin{tabular}{|c|c|c|c|}
\hline Parameter & Region 1 & Region 2 & Region 3 \\
\hline$\sigma(a), \mathrm{ksi}$ & $\begin{array}{c}\mathrm{p}[16.8+4.24 \\
(1-2 \mathrm{a} / \mathrm{w})]+8.5\end{array}$ & $\begin{array}{c}\mathrm{p}[16.8+4.24 \\
(1-2 \mathrm{a} / \mathrm{w})]+8.5\end{array}$ & $16.0 \mathrm{p}$ \\
\hline$A, \mathrm{ksi} \sqrt{\text { in }}$ & 33.2 & 33.2 & 33.2 \\
\hline$B, \mathrm{ksi} \sqrt{\mathrm{in}}$ & 20.73 & 20.73 & 20.73 \\
\hline$C,{ }^{\circ} \mathrm{F}^{-1}$ & 0.0200 & 0.0200 & 0.0200 \\
\hline$R T_{N D T_{0}},{ }^{\circ} F^{\mathrm{a}}$ & 10 & 10 & -10 \\
\hline $\begin{array}{l}\Delta N D \dot{D T T}(a=o)_{\boldsymbol{\gamma}}, \\
{ }^{\mathrm{o}} \mathrm{F} / \mathrm{EFPY}(100 \mathrm{MW})\end{array}$ & 3.6 & 2.1 & 3.1 \\
\hline $\begin{array}{l}\triangle N D T T(a=o)_{n},{ }^{\prime} \\
{ }^{\circ} \mathrm{F} / \mathrm{EFPY}(100 \mathrm{MW})\end{array}$ & 0.6 & 0.3 & 0.0 \\
\hline$\lambda(\gamma)$, in $^{-1}$ & 0.66 & 0.66 & 0.66 \\
\hline$\lambda(n)$, in $^{-1}$ & 0.15 & 0.15 & 0.15 \\
\hline$A, \mathrm{ft}^{2}$ & 1.0 & 0.8 & 100 \\
\hline$N$, flaws $/ f t^{2}$ & $7 \times 10^{-3}$ & $7 \times 10^{-3}$ & $7 \times 10^{-3}$ \\
\hline
\end{tabular}

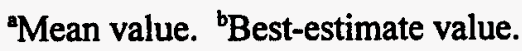




\subsection{The $\mathrm{K}_{\mathrm{Ic}}$ curve}

The values of the constants $A, B$, and $C$ in Eq. (2) correspond to the lower-bound $\mathrm{K}_{\mathrm{Ic}}$ curve given in Ref. 9 and used in the ASME Code. ${ }^{10}$ In the probabilistic analysis, a mean curve is required, and it is obtained by multiplying Eq. (2) by 1.43 (Ref. 3). The same curve is appropriate for all defined regions of the vessel. Values of $A, B$, and $C$ are given in Table 1 .

In Ref. 2, the probability of vessel failure was calculated using the above mean $\mathrm{K}_{\mathrm{lc}}$ curve and also a mean $\mathrm{K}_{\mathrm{Ic}}$ curve equal to 1.25 times the $\mathrm{K}_{\mathrm{IR}}$ curve given in Ref. 9 and used in the ASME Code for design purposes. ${ }^{8}$ The product $1.25 \mathrm{~K}_{\mathrm{IR}}$ is the mean of the dynamic-loading and crack-arrest data and thus is overly conservative for static crack initiation, which is the fracture mode of concern for HFIR. There is the possibility of low-toughness sites introducing dynamic effects, but these are believed to be accounted for in the distribution function for $\mathrm{K}_{\mathrm{Ic}}$. Thus, $\mathrm{K}_{\mathrm{IR}}$ has not been used in HFIR probabilistic evaluations other than Ref. 2.

Other mean curves have been considered. ${ }^{5,6,7}$ However, they are not generally accepted, and, furthermore, they result in less conservative values of $p(F / E)$.

\section{5 $R T_{N D T_{o}}$}

In the vessel shell regions, the value of $R T_{N D T_{o}}$ is dependent on the orientation of the flaw relative to the rolling direction $(L)$ and thickness direction $(S)$ of the plate. An axial flaw in the vessel propagating through the wall corresponds to the notch in a CVN specimen with an LS orientation. Reference 2 contains a value of $R T_{N D T_{o}}$ for the HFIR shell material for the LS orientation, and it is included in Table 1. A value for the nozzle welds is also included in Table 1. 


\section{6 $\Delta \mathbf{R T}_{\mathrm{NDT}}$}

Values of $\Delta \mathrm{RT}_{\mathrm{NDT}}$ have been determined from the HFIR vessel surveillance program for the period of time between removal/testing of surveillance specimens. Based on these data, it was determined that the rates were essentially constant with time., ${ }^{2,5}$ Thus, in Eq. (2), for the shell and weld materials,

$$
\Delta R T_{N D T}=\Delta N \dot{D} T T \cdot t
$$

where

$$
\begin{aligned}
\Delta N D T T & =\text { rate of increase of NDTT, } \\
t & =\text { operating time of vessel. }
\end{aligned}
$$

As discussed in Appendix $\mathrm{C}$ of Ref. 7, both gammas and neutrons contribute to $\triangle$ NDTT. Thus $\triangle N D T T$ at the inner surface of the vessel is divided into the two contributions to accommodate the different attenuation constants in the wall of the vessel. The value of $\Delta \mathrm{RT}_{\mathrm{NDT}}$ in Eq. (2) at the tip of the flaw is equal to the sum of the two contributions. That is,

$$
\begin{gathered}
\Delta R T_{N D T}(t, a)=\Delta N D T T(t, a)_{\gamma}+\Delta N D T T(t, a)_{n} \\
=\Delta N D T T(a=o)_{\gamma} \cdot t \cdot e^{-\lambda(\gamma) a}+\Delta N D T T(a=o)_{n} \cdot t \cdot e^{-\lambda(n) a},
\end{gathered}
$$

where

$$
\begin{array}{ll}
\lambda & =\text { attenuation constant } \\
\gamma, \boldsymbol{n} & =\text { gamma and neutron contributions }
\end{array}
$$

Values of $\triangle N D T T(\mathrm{a}=0)$ and $\lambda$ for gammas and neutrons are derived in Ref. 7 and are given in Table 1. 


\subsection{Region area and flaw density}

The number of flaws in the vessel affects the potential for failure because the more numerous the flaws the greater the chance of a flaw characterized such that it will propagate. For a defined region, the number of flaws is equal to the flaw surface density $(N)$ times the surface area of the region $(A)$. Thus, the greater the surface area the greater the potential for failure. However, some, if not all, regions will have $\mathrm{K}_{\mathrm{I}}$ and $\mathrm{K}_{\mathrm{Ic}}$ "surface" gradients. In these cases, a conservative approach is to use the maximum value of $\mathrm{K}_{\mathrm{l}} / \mathrm{K}_{\mathrm{lc}}$ and a corresponding "appropriate" area.

\subsection{Region definition}

Obviously, some judgement is required in defining the regions to be included in the analysis. Three "regions" were defined for the HFIR analysis discussed herein. Region 1 includes high-stress areas around the HB-2 and HB-3 nozzles, with an axially oriented flaw located directly above the nozzle center in the nozzle weld, where the circumferential stress is a maximum. This location does not have the maximum reduction in fracture toughness, but, as indicated in Appendix A of Ref. 6, it has the greatest potential for propagation of a flaw.

Region 1 also includes the nozzle corners, which at $50 \operatorname{EFPY}(100 \mathrm{MW})$ have about the same potential for propagation of flaws as the nozzle welds, although at earlier times the potential is less. ${ }^{6}$ The nozzle corners are included by including their "areas" as part of the nozzle weld areas. Nozzle weld areas that include the nozzle corner areas are calculated in Ref. 7. However, a review of these calculations indicated that the areas should be increased some to account for the uncertainties. The increased values, which are included in Table 1 , include an uncertainty factor of $\sim 1.8$.

The area of the outer surface of the vessel is not included in the nozzle-weld area because the attenuation of $\triangle N D T T$ from the tip of a 1.0-in. inner-surface flaw to the tip of a 1.0-in. outer-surface flaw is a factor of two, which is equivalent to a factor of ten on $P(F \mid E)$. 
Region 2 is similar to Region 1 but pertains to HB-1 and HB-4. Region 3 consists of the shell region away from the nozzles. The stresses and fluence in this region are less, but the area, and thus number of flaws, are much greater. These three regions are characterized in Table 1, and the reasons for their selection are discussed in Appendix C of Ref. 7.

For the preliminary calculations that included cladding, the cladding thickness was 0.125 inches, and the differential-expansion stress in the cladding was estimated to be $50 \mathrm{ksi}$.

\section{Brief Description of the Probabilistic Fracture-Mechanics Code FAVOR}

\subsection{Origin of FAVOR}

The computer program (code) FAVOR is an update of the OCA- $\mathrm{P}^{3}$ code, which was developed for the Nuclear Regulatory Commission (NRC) by ORNL in the early 1980's to address the PWR pressurized thermal shock (PTS) issue. " FAVOR was also developed at ORNL for the NRC. Both codes have been used by ORNL to evaluate the integrity of the HFIR vessel. ${ }^{2,5,6,7}$ FAVOR, however, is now the preferred code and was used for the study discussed in this report.

\subsection{Quality-assurance assessment}

Recently, FAVOR has undergone a formal quality-assurance assessment ${ }^{12}$ in compliance with both ORNL and NRC requirements. Both codes have been used and reviewed by organizations other than ORNL and NRC, and this further helps to validate and certify the codes.

\subsection{Basic features}

FAVOR performs both deterministic and probabilistic analyses. For the deterministic analysis, temperature, stress, stress intensity factor and fracture toughness are calculated as a function of time during an applied temperature/pressure transient and also as a function of 
position in the wall, and this can be done, of course, for any and many times in the life of the vessel. The stress intensity values are compared to the fracture toughness to determine if the flaw experiences propagation $\left(\mathrm{K}_{\mathrm{I}} \geq \mathrm{K}_{\mathrm{Ic}}\right)$.

Monte Carlo techniques are used to calculate the probability of failure. Many vessels are simulated by first simulating fracture-mechanics-related parameters to which the ratio $\mathrm{K}_{\mathrm{I}} / \mathrm{K}_{\mathrm{Ic}}$ is sensitive. A deterministic calculation is performed for each of the simulated vessels to determine which ones fail. The conditional probability of failure $[\mathrm{P}(\mathrm{F} \mid \mathrm{E})]$ is the number of failures divided by the number of vessels simulated. The probability is conditional in the sense that it pertains to a specific loading condition.

When steep radial gradients in fracture toughness and/or stresses exist in the vessel wall, it is possible that after a flaw propagates some distance the flaw will arrest. FAVOR has the ability to account for arrest; however, the conditions for arrest do not exist in the HFIR vessel. Thus, in the HFIR analysis, only the onset of propagation $\left(K_{I} \geq K_{I c}\right)$ is checked for, and this condition is designated as failure.

A vessel can be divided into regions that are characterized differently. This accommodates gradients in fluence and stress and differences in materials and propensity for the existence of flaws.

\subsection{Parameters simulated}

With the exception of flaw depth, the parameters simulated for HFIR are listed in Table 2 with their standard deviations and truncation values. Normal distributions were assumed for these parameters. The standard deviations listed are recommended by the NRC for commercial PWRs when surveillance data are not available. ${ }^{13}$

The number of flaws in a specific region with depths in the range $\Delta a_{\mathrm{i}}$ about $a_{\mathrm{i}}$ is $^{3}$

$$
P\left(\Delta a_{i}\right)=N A \int_{\Delta a_{i}}(a) B(a) d a,
$$


where

$$
\begin{aligned}
f(a) \quad= & \text { flaw-depth density function prior to final preservice inspection } \\
= & \text { (fraction of flaws with depths in the range } a \rightarrow a+\mathrm{da}) / \mathrm{da} \\
B(a) \quad & \text { probability of nondetection of flaws during final preservice } \\
& \text { inspection (detected flaws are repaired). }
\end{aligned}
$$

Table 2. Three parameters simulated in HFIR vessel probabilistic analysis

\begin{tabular}{c|c|c}
\hline Parameter & Standard deviation $^{\mathrm{a}}(\sigma)$ & Truncation $^{\circ}$ \\
\hline$R T_{N D T_{0}}$ & $17^{\circ} \mathrm{F}$ & $\mathrm{b}$ \\
\hline$\Delta \mathrm{RT}_{\mathrm{NDT}}$ & $24^{\circ} \mathrm{F}$ & $\mathrm{b}$ \\
\hline $\mathrm{K}_{\mathrm{Ic}}$ & $0.15 \mu\left(\mathrm{K}_{\mathrm{Ic}}\right)$ & $\pm 3 \sigma$ \\
\hline
\end{tabular}

'Distributions for $R T_{N D T_{o}}, \Delta \mathrm{RT}_{\mathrm{NDT}}$, and $\mathrm{K}_{\mathrm{lc}}$ are normal.

$$
{ }^{\mathrm{b}} \mathrm{\sigma}\left(\mathrm{RT}_{\mathrm{NDT}}\right)=\left[\sigma^{2}\left(R T_{N D T_{o}}\right)+\sigma^{2}\left(\Delta R T_{N D T}\right)\right]^{1 / 2} ; \text { truncated at } \pm 3 \sigma .
$$

In Ref. 7, it is concluded that there is no significant growth of flaws during the expected lifetime of the vessel, and thus a specific function for $P\left(\Delta a_{i}\right)$ is appropriate for all times in the life of the vessel. The specific function suggested in Ref. 3 and included in FAVOR is

$$
P\left(\Delta a_{i}\right)=N A \int_{\Delta a_{i}} 4.06 e^{-4.06 a}\left(0.005+0.995 e^{-2.88 a}\right) d a
$$

It is apparent from Eq. (7) that the number of flaws with depths in the range $\Delta a_{i}$ decreases rapidly with increasing depth. For HFIR, flaw depth was truncated at $1.5 \mathrm{in}$. Details of the method for simulating flaw depth, using the above distribution, are discussed in Ref. 3, and the specific flaw depths $\left(\mathrm{a}_{\mathrm{i}}\right)$ used in the HFIR analysis are given in Appendix B. Once a flaw depth is selected, the number of flaws of that depth is obtained with Eq. (7). 
All of the parameters simulated are simulated separately for each of the vessel regions considered. For each region, the mean value of $\Delta \mathrm{RT}_{\mathrm{NDT}}$ at the inner surface is attenuated through the wall in accordance with Eq. (5). At each flaw depth $(a), \mathrm{RT}_{\mathrm{NDT}}$ is simulated assuming a normal distribution, a mean value of $R T_{N D T_{o}}$ (mean) $+\Delta \mathrm{RT}_{\mathrm{NDT}}$ (mean), and

$$
\sigma\left(R T_{N D T}\right)=\left[\sigma^{2}\left(R T_{N D T_{o}}\right)+\sigma^{2}\left(\Delta R T_{N D T}\right)\right]^{1 / 2}
$$

The indicated method of calculating $\sigma\left(\mathrm{RT}_{\mathrm{NDT}}\right)$ was suggested in Ref. 14, and the justification for doing so is discussed in Ref. 15. Using the above simulated value of $\mathrm{RT}_{\mathrm{NDT}}$, a "mean" value of $\mathrm{K}_{\mathrm{Ic}}$ is calculated using the mean $\mathrm{K}_{\mathrm{Ic}} \mathrm{vs}\left(\mathrm{T}-\mathrm{RT}_{\mathrm{NDT}}\right)$ curve [Eq. (2) multiplied by 1.43]. A simulated value of $\mathrm{K}_{\mathrm{lc}}$ is obtained assuming a normal distribution characterized by the mean value of $K_{\mathrm{lc}}$ and the $\sigma\left(\mathrm{K}_{\mathrm{Ic}}\right)$ value given in Table 2 .

Flaw density is the most uncertain of all the fracture-related parameters, but it is not simulated directly in the probabilistic analysis. As discussed in Refs. 6 and 11, a log-normal distribution with a relative mode (best estimate) of 1.0, a standard deviation of 100 , and truncated at 500 was considered reasonable. This distribution has a ratio of mean to best estimate of 45 . This factor is applied to the best-estimate value of $P(F \mid E)$ to obtain a rough estimate of the mean value, which is required for comparison with criteria that are discussed in Ref. 6.

\section{Cases Calculated}

As mentioned in Sect. 3, there are two loading conditions of particular interest: the hydro test and the emergency/faulted conditions. The specified hydro-test and E/F pressures may vary over the life of the vessel, and thus a range of pressures was considered in this study. The presently specified value of $\mathrm{p}(\mathrm{HT})$ is $900 \mathrm{psid}$, and the corresponding primary system rupturedisc rating is $\sim 1100$ psi, but in Ref. 7 a lower value of p(HT) is suggested (850 psid). Also, there are plans to reduce the maximum head of the pressurizer pump, ${ }^{7}$ and this may allow $p(E / F)$, and thus $p(H T)$, to be reduced. With this in mind, a range in pressure of 700-1100 
psid was specified for the hydro test, and for $p(E / F)$ the range was $600-700$ psid. The vessel temperature specified for the hydro test was $85^{\circ} \mathrm{F}$, and that corresponding to the $\mathrm{E} / \mathrm{F}$ condition was $80^{\circ} \mathrm{F}$. The corresponding cases calculated are listed in Table 3 .

The remaining parameter to be specified for the calculations is the time in the life of the vessel $(t)$. The times selected and the corresponding values of $\Delta \mathrm{RT}_{\mathrm{NDT}}$ at the inner surface of each region are given in Table 4.

Table 3. HFIR probabilistic fracture-mechanics cases calculated.

\begin{tabular}{c|c|c}
\hline Case & $p, \mathrm{ksi}$ & $\mathrm{T}_{v},{ }^{\circ} \mathrm{F}$ \\
\hline 1 & 0.600 & 80 \\
\hline 2 & 0.650 & 80 \\
\hline 3 & 0.700 & 80 \\
\hline 4 & 0.700 & 85 \\
\hline 5 & 0.800 & 85 \\
\hline 6 & 0.850 & 85 \\
\hline 7 & 0.900 & 85 \\
\hline 8 & 1.100 & 85 \\
\hline $9^{\mathrm{a}}$ & 0.900 & 85 \\
\hline
\end{tabular}

"Calculation that included cladding.

Table 4. Times in the life of the HFIR vessel and corresponding values of $\Delta R T_{\text {NDT }}$ at the inner surface used in the probabilistic fracture-mechanics analysis.

\begin{tabular}{c|c|c|c|c|c|c}
\hline \multirow{2}{*}{$\begin{array}{c}\text { Time }(t) \\
\text { EFPY }(100 \mathrm{MW})\end{array}$} & \multicolumn{2}{|c|}{ Region 1 } & \multicolumn{2}{c}{$\Delta \mathrm{RT}_{\mathrm{NDT}}(a=0),{ }^{\circ} \mathrm{F}$} \\
\cline { 2 - 7 } & $\gamma$ & $\mathrm{n}$ & $\gamma$ & $\mathrm{n}$ & $\gamma$ & $\mathrm{n}$ \\
\cline { 2 - 8 } & 90 & 15 & 53 & 8 & 78 & \\
\hline 25 & 126 & 21 & 74 & 11 & 109 & $*$ \\
\hline 35 & 162 & 27 & 95 & 14 & 140 & $*$ \\
\hline 45 & 180 & 30 & 105 & 15 & 155 & $*$ \\
\hline 50 & 198 & 33 & 116 & 17 & 171 & \\
\hline 55 & & & &
\end{tabular}

Neutron fluence negligible. 
ORNL/TM-13303

\section{Results of Analysis}

Values of $P(F \mid E)$ for the nine cases in Table 3 and the reactor operating times in Table 4 are given in Table 5 and, for cases 1-8, are also presented graphically in Fig. 4. A comparison of cases 7 and 9 shows that inclusion of the cladding differential thermal expansion reduces $P(F \mid E)$ somewhat. This result justified leaving the cladding out of the model for the other cases.

Table 5. Calculated values of $P(F \mid F)$ for the HFIR pressure vessel

\begin{tabular}{c|c|c|c|c|c|c|c|c|c}
\hline & \multicolumn{7}{|c}{ P(F|E) } \\
$\begin{array}{c}\text { Time } \\
\text { EFPY } \\
(100\end{array}$ & \multicolumn{8}{|c}{ Case number } \\
\cline { 2 - 10 } MW) & 1 & 2 & 3 & 4 & 5 & 6 & 7 & 8 & 9 \\
\hline 25 & $2.2 \times 10^{-8}$ & $5.6 \times 10^{-8}$ & $1.1 \times 10^{-7}$ & $7.8 \times 10^{-8}$ & $2.9 \times 10^{-7}$ & $5.5 \times 10^{-7}$ & $7.3 \times 10^{-7}$ & $4.0 \times 10^{-6}$ & $3.6 \times 10^{-7}$ \\
\hline 35 & $1.1 \times 10^{-7}$ & $2.7 \times 10^{-7}$ & $4.9 \times 10^{-7}$ & $4.0 \times 10^{-7}$ & $1.2 \times 10^{-6}$ & $1.8 \times 10^{-6}$ & $2.9 \times 10^{-6}$ & $1.3 \times 10^{-5}$ & $1.6 \times 10^{-6}$ \\
\hline 45 & $4.0 \times 10^{-7}$ & $8.0 \times 10^{-7}$ & $1.4 \times 10^{-6}$ & $1.2 \times 10^{-6}$ & $3.3 \times 10^{-6}$ & $5.1 \times 10^{-6}$ & $7.6 \times 10^{-6}$ & $3.1 \times 10^{-5}$ & $5.1 \times 10^{-6}$ \\
\hline 50 & $7.6 \times 10^{-7}$ & $1.2 \times 10^{-6}$ & $2.0 \times 10^{-6}$ & $1.8 \times 10^{-6}$ & $4.9 \times 10^{-6}$ & $7.3 \times 10^{-6}$ & $1.1 \times 10^{-5}$ & $4.2 \times 10^{-5}$ & $6.2 \times 10^{-6}$ \\
\hline 55 & $1.1 \times 10^{-6}$ & $1.6 \times 10^{-6}$ & $2.7 \times 10^{-6}$ & $2.4 \times 10^{-6}$ & $6.6 \times 10^{-6}$ & $1.0 \times 10^{-5}$ & $1.5 \times 10^{-5}$ & $5.6 \times 10^{-5}$ & $1.0 \times 10^{-5}$ \\
\hline
\end{tabular}

A comparison of the results from this study with the results of the most recent previous study ${ }^{6}$ that did not include the effect of gammas on the space-wise distribution of $\triangle N D T T$ shows the latest values of $\mathrm{P}(\mathrm{F} \mid \mathrm{E})$ to be essentially the same. In Ref. 7, an attempt was made to include the effect of gammas, and the result was a $40 \%$ increase in $P(F \mid E)$ compared to the results in Ref. 6. Thus, the more precise evaluation in this study yielded values of $P(F \mid E)$ that are about $30 \%$ less than those in the most recent previous study, ${ }^{7}$ which included an estimation of the gamma effect, even though the Region 1 and Region 2 areas in this study were greater by $82 \%$. This reflects the conservatism associated with the extrapolations in Ref. 7 . 
ORNL/TM-13303

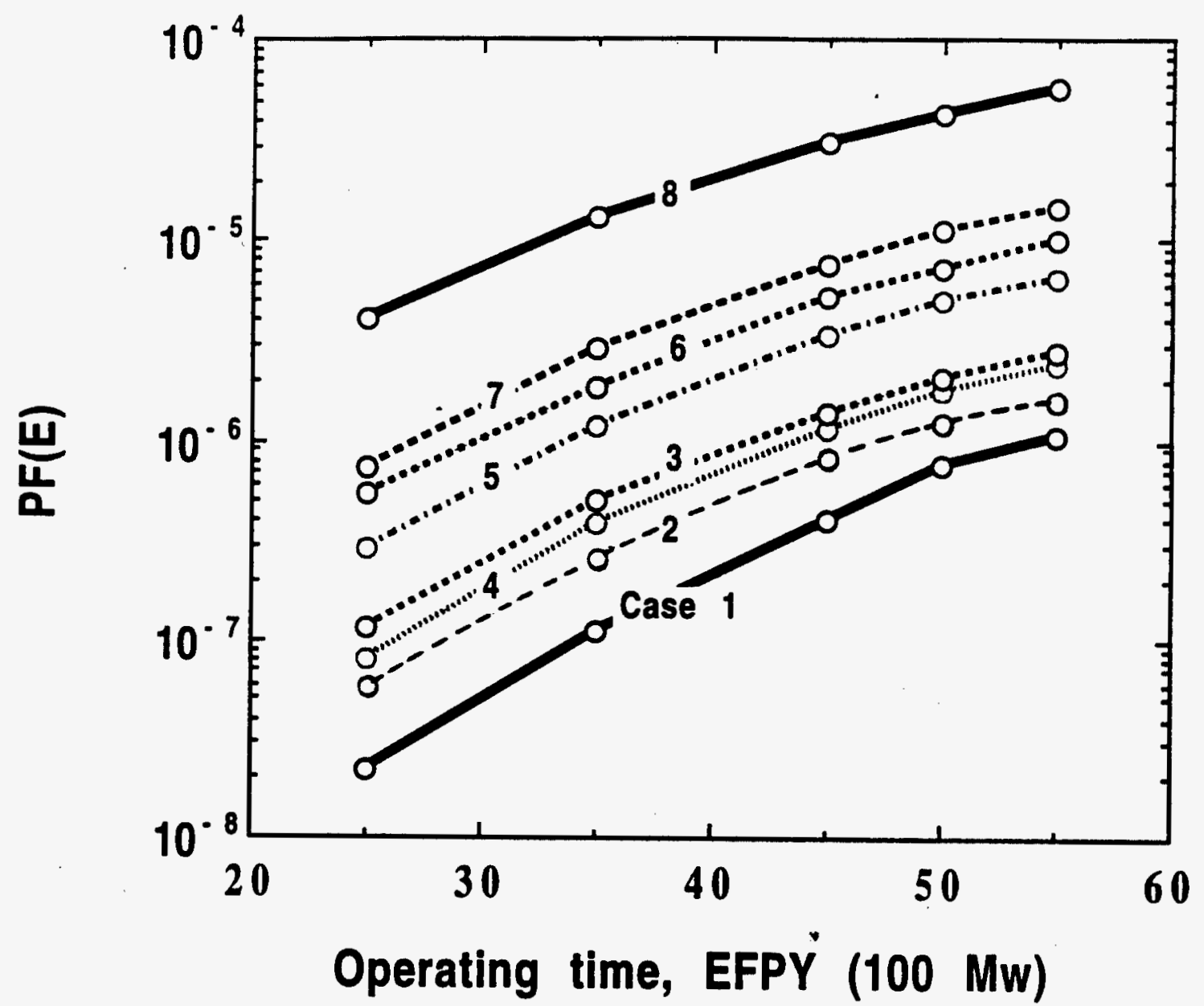

\begin{tabular}{c|c|c}
\hline $\begin{array}{c}\text { Case } \\
\text { number }\end{array}$ & $\begin{array}{c}\text { Pressure } \\
\text { psid }\end{array}$ & $\begin{array}{c}\text { Temperature } \\
{ }^{\circ} \mathrm{F}\end{array}$ \\
\hline 1 & 600 & 80 \\
\hline 2 & 650 & 80 \\
\hline 3 & 700 & 80 \\
\hline 4 & 700 & 85 \\
\hline 5 & 800 & 85 \\
\hline 6 & 850 & 85 \\
\hline 7 & 900 & 85 \\
\hline 8 & 1100 & 85 \\
\hline
\end{tabular}

Fig. 4. Conditional probability of failure $[P(F \mid E)]$ of HFIR pressure vessel vs operating time. 
ORNL/TM-13303

Contrary to the results in Ref. 7, this study indicates that the shell region, with its much larger area and thus number of flaws but lower stress and $\triangle N D T T$, compared to the other two regions, contributes very little to $P(F \mid E)$. This difference, also, is attributed to the extrapolations that were necessary in Ref. 7.

Results of the analysis also show (Figs. 5 and 6) that the range of flaw depths resulting in most of the failures is such that truncation of the flaw-depth distribution function at 1.5 in. was reasonable because relatively few failures occur with flaws in the increment $\left(\Delta a_{i}\right)$ having an average flaw depth equal to 1.5 in.

Another result of interest is obtained by comparing $P(F \mid E)$ values for the hydro test at time $\mathrm{t}(\mathrm{HT})$ and the $\mathrm{E} / \mathrm{F}$ conditions at time $\mathrm{t}(\mathrm{HT})+\Delta \mathrm{t}$, where $\mathrm{t}(\mathrm{HT})$ and $\Delta \mathrm{t}$ are the time of the hydro test and the time between hydro tests. The former value of $P(F \mid E)$ should be greater than the latter to provide further assurance that the vessel will not fail during the time between hydro tests. In Ref. 7, the proposed hydro-test conditions for vessel life extension beyond 26 $\operatorname{EFPY}(100 \mathrm{MW})$ are $\mathrm{p}(\mathrm{HT})=850 \mathrm{psi}, \mathrm{T}_{\mathrm{v}}(\mathrm{HT})=85^{\circ} \mathrm{F}$, and $\Delta \mathrm{t}=3.0 \mathrm{EFPY}(100 \mathrm{MW})$; the $\mathrm{E} / \mathrm{F}$ conditions are $\mathrm{p}(\mathrm{E} / \mathrm{F})=679 \mathrm{psi}$ and $\mathrm{T}_{\mathrm{v}}(\mathrm{E} / \mathrm{F})=80^{\circ} \mathrm{F}$. For convenience, let $\Delta \mathrm{t}=5 \mathrm{EFPY}(100$ $\mathrm{MW})$ and $\mathrm{p}(\mathrm{E} / \mathrm{F})=700 \mathrm{psi}$, both values being conservatively large, as indicated above. From Table 5, using Cases $6(\mathrm{HT})$ and $3(\mathrm{E} / \mathrm{F}), \mathrm{t}(\mathrm{HT})=45$, and $\mathrm{t}(\mathrm{E} / \mathrm{F})=50 \mathrm{EFPY}(100 \mathrm{MW})$, $\mathrm{P}(\mathrm{F} \mid \mathrm{E})(\mathrm{HT})=5.1 \times 10^{-6}$ and $\mathrm{P}(\mathrm{F} \mid \mathrm{E})(\mathrm{E} / \mathrm{F})=2.0 \times 10^{-6}$. Thus, $\mathrm{P}(\mathrm{F} \mid \mathrm{E})(\mathrm{HT})>\mathrm{P}(\mathrm{F} \mid \mathrm{E})(\mathrm{E} / \mathrm{F})$ by a factor of $\sim 2.5$. This is an additional margin over that associated with the deterministic derivation of the hydro-test conditions and is the result of using, perhaps, excessively large uncertainty factors in the deterministic analysis.

Frequencies of failure $[\phi(F)]$ can be estimated for the hydro-test (HT) and emergency/faulted (E/F) loading conditions using values of $P(F \mid E)$ from Table 5 or Fig. 4, frequencies of events $[\phi(E)]$ from Refs. 6 and 7, and the relation ${ }^{6}$

$$
\phi(F)=\phi(E) P(F \mid E)
$$




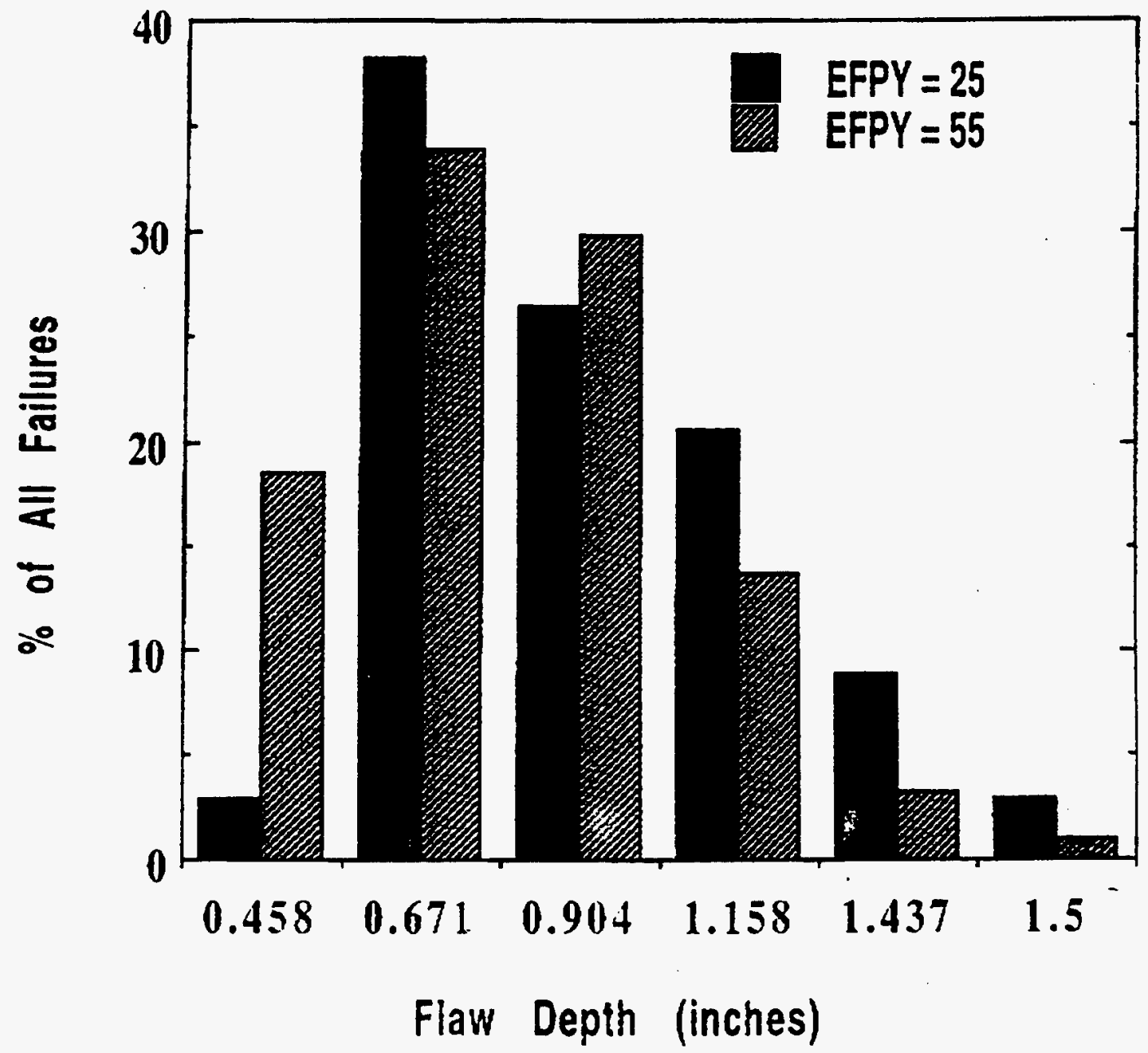

Fig. 5. Histogram of percent failures vs average flaw depth for Case 7. 


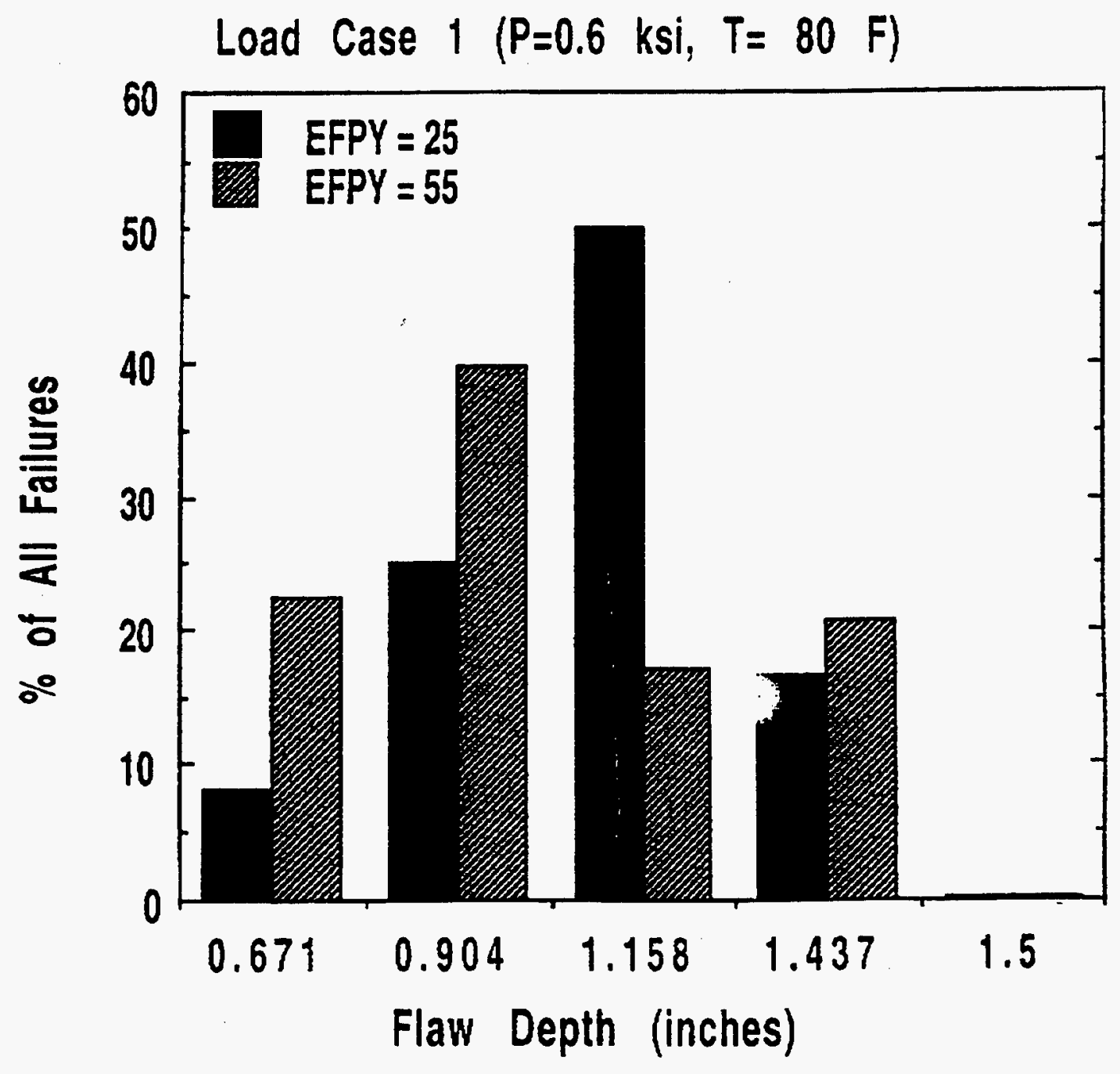

Fig. 6. Histogram of percent failures vs average flaw depth for Case 1. 
The largest value of $\mathrm{P}(\mathrm{F} \mid \mathrm{E})(\mathrm{HT})$ corresponds to the time of the last hydro test, which occurs at $50 \mathrm{EFPY}(100 \mathrm{MW})-\Delta \mathrm{t}$, where, as indicated above, $\Delta \mathrm{t}=3 \mathrm{EFPY}(100 \mathrm{MW})$. Thus, $\mathrm{t}(\mathrm{HT})$ $=47 \mathrm{EFPY}(100 \mathrm{MW}), \mathrm{P}(\mathrm{F} \mid \mathrm{E})(\mathrm{HT})=5.9 \times 10^{-6}, \phi(\mathrm{E})=0.333 / \mathrm{EFPY}(100 \mathrm{MW})$, and

$$
\phi(F)(H T)=0.333 \times 5.9 \times 10^{-6}=2.0 \times 10^{-6} / E F P Y(100 M W) .
$$

The largest value of $P(F \mid E)(E / F)$ corresponds to the end of the life-extension period; thus, $t(E / F)=50$ EFPY $(100 \mathrm{MW})$. From Ref. 6, $\phi(E)=10^{-2} / E F P Y(100 \mathrm{MW})$, and from Table 5, $P(F \mid E)(E / F)=2.0 \times 10^{-6}$. Using Eq. (9),

$$
\phi(F)(E / F)=10^{-2} \times 2.0 \times 10^{-6}=2.0 \times 10^{-8} / E F P Y(100 \mathrm{MW}) .
$$

The above values of $P(F \mid E)$ and thus $\phi(F)$ are best-estimate values. As discussed in Ref. 6, the mean value of the frequency of failure $[\phi(F)]$ is required for comparison with the tentatively specified limiting values, and the mean value of $P(F \mid E)$ is obtained by multiplying the best-estimate value by the ratio mean flaw density/best-estimate flaw density. The value of this ratio for HFIR is $45 .^{6}$ Thus,

$$
\begin{gathered}
\bar{\phi}(F)(H T)=2.0 \times 10^{-6} \times 45=9.0 \times 10^{-5} / E F P Y(100 \mathrm{MW}), \\
\bar{\phi}(F)(E / F)=2.0 \times 10^{-8} \times 45=9.0 \times 10^{-7} / E F P Y(100 M W)
\end{gathered}
$$

The maximum permissible values tentatively specified in Ref. 6 are

$$
\begin{aligned}
& \bar{\phi}(F)(H T, M P)=1 \times 10^{-4} / E F P Y(100 M W) \\
& \bar{\phi}(F)(E / F, M P)=5 \times 10^{-6} / E F P Y(100 M W)
\end{aligned}
$$

Thus, the criteria are satisfied. 


\section{Discussion and Conclusions}

In Refs. 6 and 7, it is concluded that the life of the HFIR vessel can be extended to 50.EFPY $(100 \mathrm{MW})$. This study confirms that conclusion because the values of $P(F \mid E)$ and $\Phi(F)$ calculated in this study are less than those calculated in Ref. 7.

The derivation of the hydro-test conditions is based on a deterministic analysis that requires the potential for vessel failure during the hydro test to be at least equal to that for worst-case normal operating $(\mathrm{E} / \mathrm{F})$ conditions during the time between hydro tests. This implies that $\mathrm{P}(\mathrm{F} \mid \mathrm{E})$ for hydro-test conditions must be at least equal to that for the $\mathrm{E} / \mathrm{F}$ conditions during the time between hydro tests. This criterion is satisfied because the results of this study indicate that $\mathrm{P}(\mathrm{F} \mid \mathrm{E})(\mathrm{HT}) \approx 3 \mathrm{P}(\mathrm{F} \mid \mathrm{E})(\mathrm{E} / \mathrm{F})$, where the $\mathrm{E} / \mathrm{F}$ condition is taken at time $\mathrm{t}(\mathrm{HT})+$ $\Delta \mathrm{t}$.

\section{References}

1. J. R. McWherter, R. E. Schappel, and J. R. McGuffey, HFIR Pressure Vessel and Structural Components Material Surveillance Program, Oak Ridge National Laboratory, ORNL-TM-1372, January 1966.

2. R. D. Cheverton, J. G. Merkle, and R. K. Nanstad, Evaluation of HFIR PressureVessel Integrity Considering Radiation Embrittlement, Oak Ridge National Laboratory, ORNL/TM-10444, April 1988.

3. R. D. Cheverton and D. G. Ball, OCA-P, A Deterministic and Probabilistic FractureMechanics Code for Application to Pressure Vessels, NUREG/CR-3618 (ORNL5991), Martin Marietta Energy Systems, Inc., Oak Ridge National Laboratory, May 1984.

4. T. L. Dickson, FAVOR, Oak Ridge National Laboratory, ORNL/NRC/LTR-94-1, February 1994. 
5. R. D. Cheverton and R. K. Nanstad, Evaluation of HFIR Vessel Surveillance Data and Hydro-Test Conditions, Oak Ridge National Laboratory, ORNL/TM-12758, August 1994.

6. R. D. Cheverton, An Evaluation of Life Extension of the HFIR Pressure Vessel, Oak Ridge National Laboratory, ORNL/TM-12877, December 1994.

7. R. D. Cheverton, An Evaluation of Life Extension of the HFIR Pressure Vessel, Supplement 1, Oak Ridge National Laboratory, ORNL/TM-12877S1, August 1996.

8. ASME Boiler and Pressure Vessel Code, Section III, Division 1, Appendix G, 1992 Edition.

9. T. U. Marston, Ed., Flaw Evaluation Procedures: ASME Section XI, EPRI NP-719$S r$, Electric Power Research Institute, Palo Alto, CA, August 1978, including corrections dated April 14, 1980.

10. ASME Boiler and Pressure Vessel Code, Section XI, Division 1, Appendix A, 1992 Edition.

11. D. L. Selby, et. al., Pressurized Thermal Shock Evaluation of the H. B. Robinson Nuclear Power Plant, NUREG/CR-4183 (ORNL/TM-9567), Martin Marietta Energy Systems, Inc., Oak Ridge National, September 1985.

12. R. D. Cheverton, Quality Assurance Program for the FAVOR Code, Delta-21 Resources, Inc., RDC/LTR-96-2, August 7, 1996.

13. U. S. Nuclear Regulatory Commission, "Pressurized Thermal Shock (PTS), Secy-82465, Attachment A," Letter to USNRC Commissioners, November 23, 1982.

14. Code of Federal Regulations, Title 10, Part 50, Section 50.61 and Appendix G. 
ORNL/TM-13303

15. Yardley Beers, Introduction to the Theory of Error, Addison-Wesley Publishing Co., Inc., 1962. 


\section{APPENDIX A}

\section{DERIVATION OF STRESSES IN REGIONS OF VESSEL DEFINED FOR PROBABILISTIC FRACTURE-MECHANICS ANALYSIS}

\section{Regions 1 and 2 (Nozzle Welds above HB-2 and HB-3)}

Stresses for Regions 1 and 2 include membrane and bending stresses, due to internal pressure, and residual stresses. It is assumed that the residual stress is uniform through the wall (a conservative assumption), and that the bending stress varies linearly through the wall. Thus, the total circumferential stress as a function of position through the wall is

$$
\sigma_{T}=p\left(\frac{\sigma_{m}}{p}\right)+p\left(\frac{\sigma_{b}}{p}\right)\left(1-\frac{2 a}{\omega}\right)+\sigma_{r},
$$

where

$$
\begin{array}{ll}
\sigma_{\mathrm{T}} & =\text { total stress in nozzle weld } \\
\sigma_{\mathrm{m}} & =\text { pressure-induced membrane stress } \\
\sigma_{\mathrm{b}} & =\text { pressure-induced bending stress at inner surface of vessel wall } \\
\sigma_{\mathrm{r}} & =\text { residual stress in weld } \\
\mathrm{p} & =\text { primary-system pressure } \\
\mathrm{a} & =\text { radial position in wall } \\
\omega & =\text { wall thickness }
\end{array}
$$

From Ref. 2, $\left(\frac{\sigma_{m}}{p}\right)=16.8,\left(\frac{\sigma_{b}}{p}\right)=4.24, \sigma_{r}=8.5 \mathrm{ksi}$ 
Thus,

$$
\sigma_{T}=p[16.8+4.24(1-2 a / \omega)]+8.5
$$

\section{Region 3 (Shell away from Nozzles)}

The only stress is the pressure-induced membrane stress, which is

$$
\sigma_{m}=\frac{p r}{\omega}=p \frac{48}{3}=16.0 p
$$




\section{APPENDIX B}

\section{FLAW-DEPTH INCREMENTS USED IN FLAW-DEPTH DISTRIBUTION FUNCTION [(EQ. (7)]}

The average flaw depth $\left(a_{i}\right)$ used in the flaw-depth distribution function [Eq. (7)] was truncated at 1.5 in. Eight values of $a_{i}$, including 1.5 in., were specified. These values are given in Table B.1. The relative number of flaws in each increment $\Delta \mathrm{a}_{i}$, consistent with Eq. (7), and the cumulative values are also included in Table B.1.

Table B.1. Flaw-depth data used for HFIR

\begin{tabular}{c|c|c}
\hline $\mathrm{a}_{\mathrm{i}}$ (in.) & $\mathrm{A}_{\mathrm{i}}{ }^{a}$ & $\Sigma_{\mathrm{i}} \mathrm{A}_{\mathrm{i}}$ \\
\hline 0.0850 & 0.69122 & 0.69122 \\
\hline 0.2630 & 0.22307 & 0.91428 \\
\hline 0.4577 & 0.06446 & 0.97874 \\
\hline 0.6707 & 0.01656 & 0.99530 \\
\hline 0.9036 & 0.00377 & 0.99907 \\
\hline 1.1585 & 0.00076 & 0.99983 \\
\hline 1.4373 & 0.00014 & 0.99997 \\
\hline 1.5000 & 0.00003 & 1.00000 \\
\hline
\end{tabular}

${ }^{a} \mathrm{~A}_{\mathrm{i}}=\int_{\Delta a_{i}} f(a) B(a) d a / \int_{0}^{w} f(a) B(a) d a$ 


\section{INTERNAL DISTRIBUTION}

\begin{tabular}{llll} 
1. & W. K. Brown & 33. & J. E. Lee \\
2. & S. E. Burnette & 34. & M. A. Linn \\
3. & M. H. Carpenter & 35. & R. S. McKeehan \\
4. & S. J. Chang & 36. & J. G. Merkle \\
5-9. & R. D. Cheverton & 37. & L. D. Merryman \\
10. & D. H. Cook & 38. & R. K. Nanstad \\
11. & R. E. Daniels (DOE-ORO) & 39. & J. V. Pace III \\
12. & T. L. Dickson & 40. & L. D. Proctor \\
13. & H. R. Fair (DOE-ORO) & 41. & J. B. Richard \\
14. & M. B. Farrar & 42. & R. B. Rothrock \\
15. & K. Farrell & 43. & R. M. Stinnett \\
16. & G. F. Flanagan & 44. & B. S. Willis (DOE-ORO) \\
17. & H. A. Glovier & 45. & RRD-DCC \\
18. & R. E. Hale & 46. & Document Reference Section \\
19. & R. W. Hobbs & $47-48$. Laboratory Records \\
20-30. J. R. Inger & 49. & Laboratory Records (RC) \\
31. & H. T. Kerr & \multicolumn{3}{l}{} \\
32. & M. W. Kohring & \multicolumn{3}{l}{}
\end{tabular}

\section{EXTERNAL DISTRIBUTION}

51. M. A. Hutmaker, Jr., Office of Nuclear Energy, NE-47-GTN, Department of Energy, Washington, DC, 20585

52. Office of Assistant Manager for Energy Research and Development, Department of Energy-ORO, Oak Ridge, TN, 37831 


\section{M98054251}

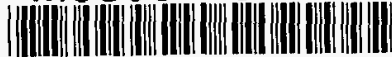

Report Number (14) ORNL/TM -13303
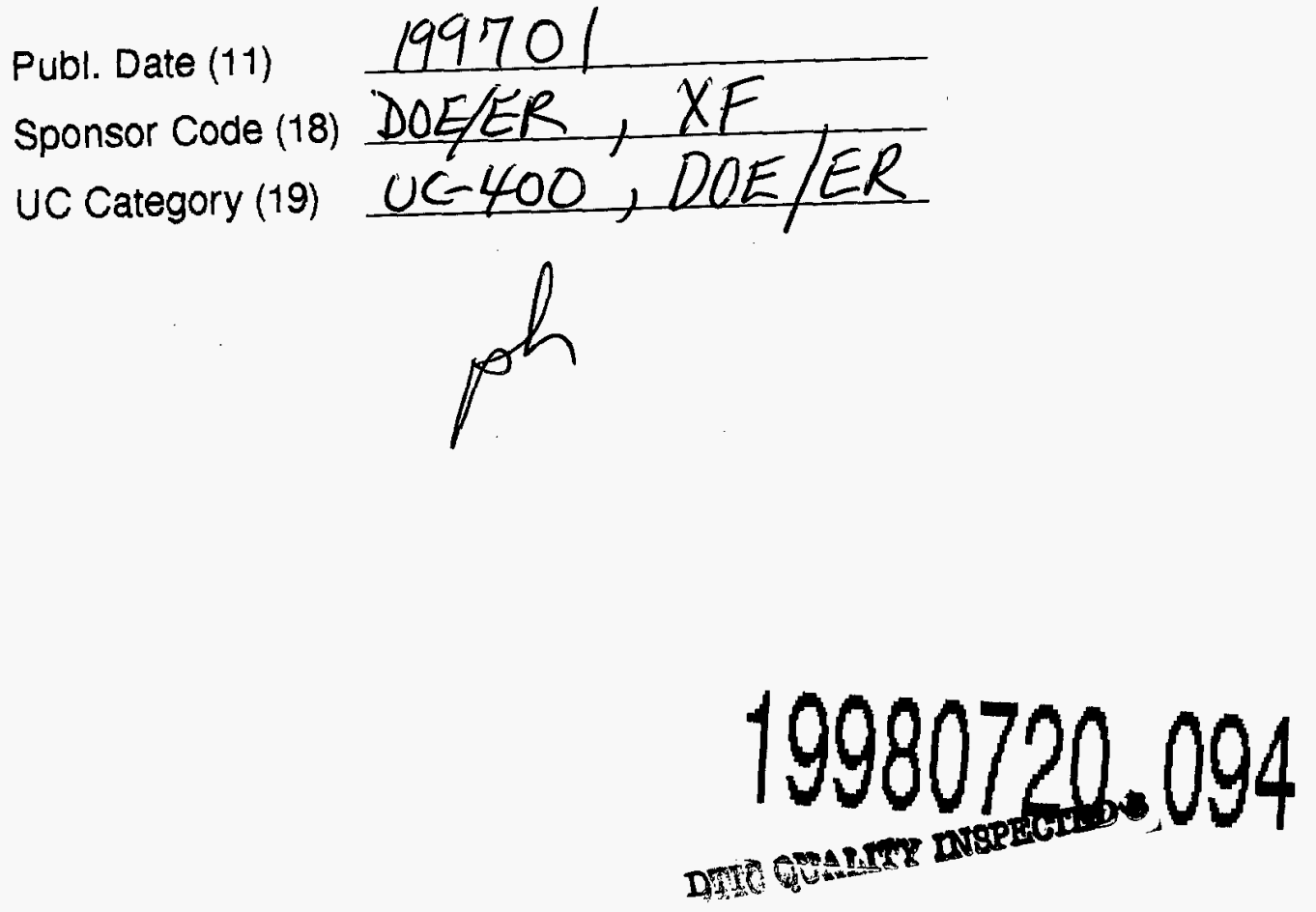